\title{
The efficacy and safety of alectinib in the treatment of ALK + NSCLC: a systematic review and meta-analysis
}

This article was published in the following Dove Press journal:

OncoTargets and Therapy

\author{
Junsheng Fan ${ }^{1,2, *}$ \\ Zengfei Xia ${ }^{1, *}$ \\ Xiaoli Zhang ${ }^{1, *}$ \\ Yuqing Chen' \\ Ruolan Qian' \\ Sihan Liu' \\ Danming You' \\ Jian Zhang' \\ Peng Luo'
}

'Department of Oncology, Zhujiang

Hospital of Southern Medical

University, Guangzhou, China;

${ }^{2}$ Department of Respiratory Medicine, Shanghai Tenth People's Hospital,

Tongji University, Shanghai, China

*These authors contributed equally to this work
Correspondence: Jian Zhang; Peng Luo Zhujiang Hospital of Southern Medical University, 253 Industry Road, Guangzhou, Guangdong, China Email blacktiger@139.com; luopeng@smu.edu.cn
Background: Alectinib is a second-generation anaplastic lymphoma kinase (ALK) inhibitor approved by the US Food and Drug Administration to treat crizotinib-refractory non-small cell lung cancer. We performed this meta-analysis to synthesize the results of different clinical trials to evaluate the efficacy and safety of alectinib.

Methods: A search of 3 databases, including PubMed, Web of Science, and the Cochrane Library, was performed from the inception of each database through September 5, 2017. We have pooled the overall response rate (ORR), disease control rate, progression-free survival, and intracranial ORR to evaluate the efficacy of alectinib. Discontinuation rate, rate of dose reduction or interruption due to adverse events as well as the incidence of several adverse events were aggregated to evaluate its safety.

Results: A total of 8 studies with 626 patients have been included in our study. The pooled efficacy parameters are as follows: ORR 70\% (95\% CI: $57 \%$ to $82 \%$ ), disease control rate $88 \%$ ( $95 \%$ CI: $82 \%$ to $94 \%$ ), progression-free survival 9.36 months ( $95 \%$ CI: $7.38 \%$ to $11.34 \%$ ), and intracranial ORR 52\% (95\% CI: 45\% to 59\%). ALK inhibitor-naïve patients tend to have better responses than crizotinib-pretreated patients. The aggregate discontinuation rate is $7 \%(95 \%$ CI: $4 \%$ to $10 \%$ ), and the pooled rate of dose reduction or interruption is $33 \%$ (95\% CI: $24 \%$ to $42 \%$ ). The incidences of most adverse events were relatively low, while the incidences of 2 frequently reported adverse events, myalgia (18\%) and anemia (25\%), were even higher than with the first-generation ALK inhibitor crizotinib.

Conclusion: Generally, alectinib is a drug with preferable efficacy and tolerable adverse effects, and it is suitable for the treatment of intracranial metastases.

Keywords: alectinib, anaplastic lymphoma kinase, ALK, ALK inhibitor, non-small cell lung cancer, NSCLC, meta-analysis

\section{Introduction}

Non-small cell lung cancer (NSCLC) accounts for $\sim 85 \%$ of all lung cancers diagnosed each year, most of which were adenocarcinoma. ${ }^{1,2}$ Platinum-based chemotherapies have long been the first-line treatment for advanced NSCLC. ${ }^{1,3}$ However, due to various adverse effects of chemotherapies as well as increased resistance of tumors, the prognosis of advanced NSCLC remains dismal. ${ }^{1,4-7}$ This has called for novel therapies with higher efficacy and safety results.

Echinoderm microtubule-associated protein like 4 (EML4)-anaplastic lymphoma kinase (ALK) fusion protein was first discovered in NSCLC tissues in $2007 .{ }^{8}$ It is believed to play a vital role in the carcinogenesis of NSCLC in $~ 5 \%$ of patients. ${ }^{9}$ In vitro experiments have confirmed the activation of several downstream oncogenic pathways 
caused by the EML4-ALK fusion protein, including PI3K, JAK/STAT, and RAS/MEK/ERK pathways. ${ }^{10}$ Therefore, ALK-rearrangement is considered as a novel therapeutic target for NSCLC. Crizotinib was the first Food and Drug Administration (FDA)-approved ALK inhibitor (ALKi) used to treat NSCLC and has better efficacy and safety results compared with conventional chemotherapy. ${ }^{9,11}$ However, most patients treated with crizotinib acquired resistance within 1 year. ${ }^{9}$ Potential mechanisms of crizotinib resistance can be classified into primary and secondary resistances. ${ }^{12}$ Primary resistance may result from rearrangements of ALK gene with other genes such as KIF5B, TPR, HIP1, and SQSTM1, ${ }^{13}$ while secondary resistance (acquired resistance) may be caused by ALK kinase domain mutation, increased ALK gene copy and activation of other cancer-related signaling pathways. ${ }^{12,13}$ Additionally, central nervous system (CNS) metastases are not uncommon in NSCLC patients, while the intracranial efficacy of the first-generation ALKi crizotinib was not that satisfying. ${ }^{14,15}$ Some severe adverse effects, such as erythema multiforme and acute interstitial lung disease have also appeared in some of the patients treated with crizotinib. ${ }^{16,17}$ These results have called for the development of next-generation ALKis.

Several second-generation ALKis, such as ceritinib, alectinib, and brigatinib, have been developed to overcome crizotinib resistance. ${ }^{18}$ Ceritinib is recommended as the second-line treatment for patients progressed after first-line crizotinib. ${ }^{19}$ While brigatinib is an inhibitor of both ALK and epidermal growth factor receptor. ${ }^{13}$ Alectinib is a secondgeneration ALKi with higher potency and selectivity. ${ }^{13}$ In vitro experiments have proved that the inhibitory effect of alectinib on ALK outperforms crizotinib. ${ }^{18,20}$ It is believed that one of the major differences between next-generation ALKis is their spectrum of inhibitory effects on secondary resistance mutations. ${ }^{21}$ In vitro experiments have confirmed the inhibitory effect of alectinib on several resistance mutations, including L1196M, C1156Y, R1275Q, and F1174L, in which L1196M was considered as the gatekeeper mutation of crizotinib-refractory NSCLC. ${ }^{20,22}$

Currently, several clinical trials of alectinib from Phase I to III have been published. ${ }^{15,23-29}$ However, the efficacy and safety data of these clinical trials are not identical. Only 2 systematic reviews have studied the efficacy and safety of crizotinib in ALK-positive (ALK+) NSCLC patients. ${ }^{30,31}$ The systematic review and meta-analysis of the efficacy and safety of alectinib have not yet been reported. In our current study, we attempted to pool the efficacy (overall response rate $[\mathrm{ORR}]$, disease control rate [DCR], progression-free survival [PFS], and intracranial ORR) and safety parameters (discontinuation rate, rate of dose reduction or interruption, and event rate of adverse events) in order to synthesize the results of different studies and provide the least biased evidence for the clinical use of alectinib.

\section{Methods}

This research was performed in compliance with the preferred reporting items for systematic reviews and meta-analysis statement for reporting systemic reviews in order to reduce potential risk of bias (ROB). ${ }^{32}$

\section{Search strategy}

A search of 3 databases, including PubMed, Web of Science, and the Cochrane Library was performed from the inception of each database through September 5, 2017. All MeSH terms and entry terms of the keywords (alectinib, NSCLC) were used in the search strategies.

The following is an example of the search strategy used on PubMed: ("Non-Small Cell Lung Cancer" OR "NonSmall Cell Lung Carcinoma" OR "Non Small Cell Lung Carcinoma" OR "Non-Small-Cell Lung Carcinoma" OR "Nonsmall Cell Lung Cancer" OR "Non-Small-Cell Lung Carcinomas" OR "Non-Small-Cell Lung Carcinoma" OR "NSCLC") AND ("alectinib" OR “Alecensa" OR “RO5424802” OR “CH5424802”).

The "Advanced search" capabilities of the different databases were used, and no restrictions on study language were applied.

We also reviewed the references of the retrieved articles, and any relevant studies in the reference lists were also included according to the inclusion and exclusion criteria. If the databases failed to provide enough information that we needed, we tried to contact the corresponding authors by email to get more data.

\section{Inclusion and exclusion criteria}

The inclusion criteria were as follows: 1) types of studies: clinical trials, 2) types of participants: ALK+ NSCLC patients, 3 ) types of interventions: patients were treated with alectinib at any dose, 4) types of outcome measures: PFS, ORR, and DCR, or at least 1 of them should be provided in the included studies. Studies that provided the event rate of various adverse events as well as discontinuation rate and rate of dose reduction or interruption after alectinib treatment were also included, and 5) full text was available.

The exclusion criteria were as follows: duplicate publications, literature reviews, systematic reviews, case reports 
or case series, animal experiments or cell experiments, and required data were not available even after correspondence with the authors.

\section{Quality assessment of included studies}

Two reviewers (JF and ZX) evaluated all of the included studies independently after reading the full text of each study. We used the Cochrane collaboration ROB tool to evaluate the quality of the included randomized controlled trials (RCTs). ${ }^{33}$ The overall ROB of a study was considered "low" if $>4$ items in the Cochrane collaboration ROB tool were rated as "low risk." The overall ROB of a study was considered "moderate" if 2 or 3 items in the Cochrane collaboration ROB tool were rated as "low risk." The overall ROB of a study was considered "high" if $<2$ items in the Cochrane collaboration ROB tool were rated as "low risk" or if $>1$ item was rated as "high risk." We used the Newcastle-Ottawa scale (NOS) to assess the quality of the included single-arm clinical trials and non-RCTs. ${ }^{34}$ The overall quality of a study was considered to be "poor" if the total NOS score was $<4$. Studies with an NOS score between 4 and 6 were considered to be "moderate," and those with an NOS score between 7 and 9 were considered to be of high quality.

\section{Data extraction}

With a data extraction template designed in advance, the following data were collected by the 2 reviewers (JF and ZX) independently: the first author's name, publication year, the study design, sample size, dose of alectinib treatment, median PFS as well as 95\% CI, ORR, DCR, discontinuation rate, rate of dose reduction or interruption, event rate of adverse events, and the information needed to evaluate the quality of each study. Any discrepancies during study selection and data extraction were resolved by discussion and consultation with another reviewer (PL).

\section{Statistical analysis}

All statistical analyses were conducted using Review Manager 5.3 (Cochrane Collaboration) and STATA 12.0 software (Stata Corp., College Station, TX, USA). Average PFS was used for the summary measure for PFS. The event rate of other parameters directly served as the summary measures. Inter-study heterogeneity was assessed using Chi-square test and $I^{2}$ statistic. A $p$-value $>0.1$ and an $I^{2}<50 \%$ indicates that the heterogeneity was not statistically significant, thus the fixed-effect model was used. If the $p$-value was $<0.1$ and an $I^{2}$ no $<50 \%$, there is a significant heterogeneity between the studies, therefore the random-effect model was applied. Funnel plots were used to display the publication bias. Begg's and Egger's tests were used to evaluate the publication bias quantitatively.

\section{Results \\ Characteristics and quality assessment of included studies}

A total of 443 references have been identified after database searching (PubMed 189, Web of Science 218, Cochrane Library 36). There were 268 references left after deduplication. Of these, 244 references, which included animal experiments or cell experiments, diagnostic tests, case reports or case series, as well as other irrelevant studies were excluded according to the inclusion and exclusion criteria. Finally, a total of 8 clinical trials (2 RCTs and 6 single-arm trials) with 626 patients ( 255 in the 2 RCTs and 371 in the 6 single-arm trials) were included after reading the full text (Figure 1). The general characteristics of the included studies are listed in Table 1. The details of quality assessment are listed in Table S1.

\section{Outcome evaluation and meta-analysis} The efficacy of alectinib

The pooled ORR of ALK+ NSCLC patients treated with alectinib is $70 \%$ (95\% CI: $57 \%$ to $82 \%$ ). Subgroup analysis showed that patients who never received ALKi treatment tend to have higher ORR than crizotinib-pretreated patients (87\%, $95 \%$ CI: $81 \%$ to $92 \%$ vs $52 \%, 95 \%$ CI: $46 \%$ to $58 \%$; Figure 2). The pooled DCR is $88 \%$ (95\% CI: $82 \%$ to $94 \%)$, and subgroup analysis showed that patients who never received ALKi treatment tend to have higher DCR than crizotinib-pretreated patients (95\%, 95\% CI: $89 \%$ to $100 \%$ vs $83 \%, 95 \%$ CI: $76 \%$ to $89 \%$; Figure 3 ). The pooled average PFS is 9.36 months (95\% CI: $7.38 \%$ to $11.34 \%$; Figure 4 ). For the ORR of alectinib-treated ALK+ NSCLC patients with brain metastases, the pooled result is $52 \%$ (95\% CI: $45 \%$ to $59 \%$ ). Subgroup analysis showed that ALKi-naïve patients tend to have higher ORR than crizotinib-pretreated patients $(59 \%$, $95 \%$ CI: $47 \%$ to $71 \%$ vs $48 \%$, 95\% CI: $38 \%$ to $57 \%$; Figure 5 ).

\section{The safety of alectinib}

Several parameters have been used to evaluate the safety of alectinib. Some patients may require a dose reduction or interruption, or even the total discontinuation of the treatment due to various adverse events. The pooled discontinuation rate is $7 \%(95 \% \mathrm{CI}$ : $4 \%$ to $10 \%$; Figure 6$)$, while the pooled 


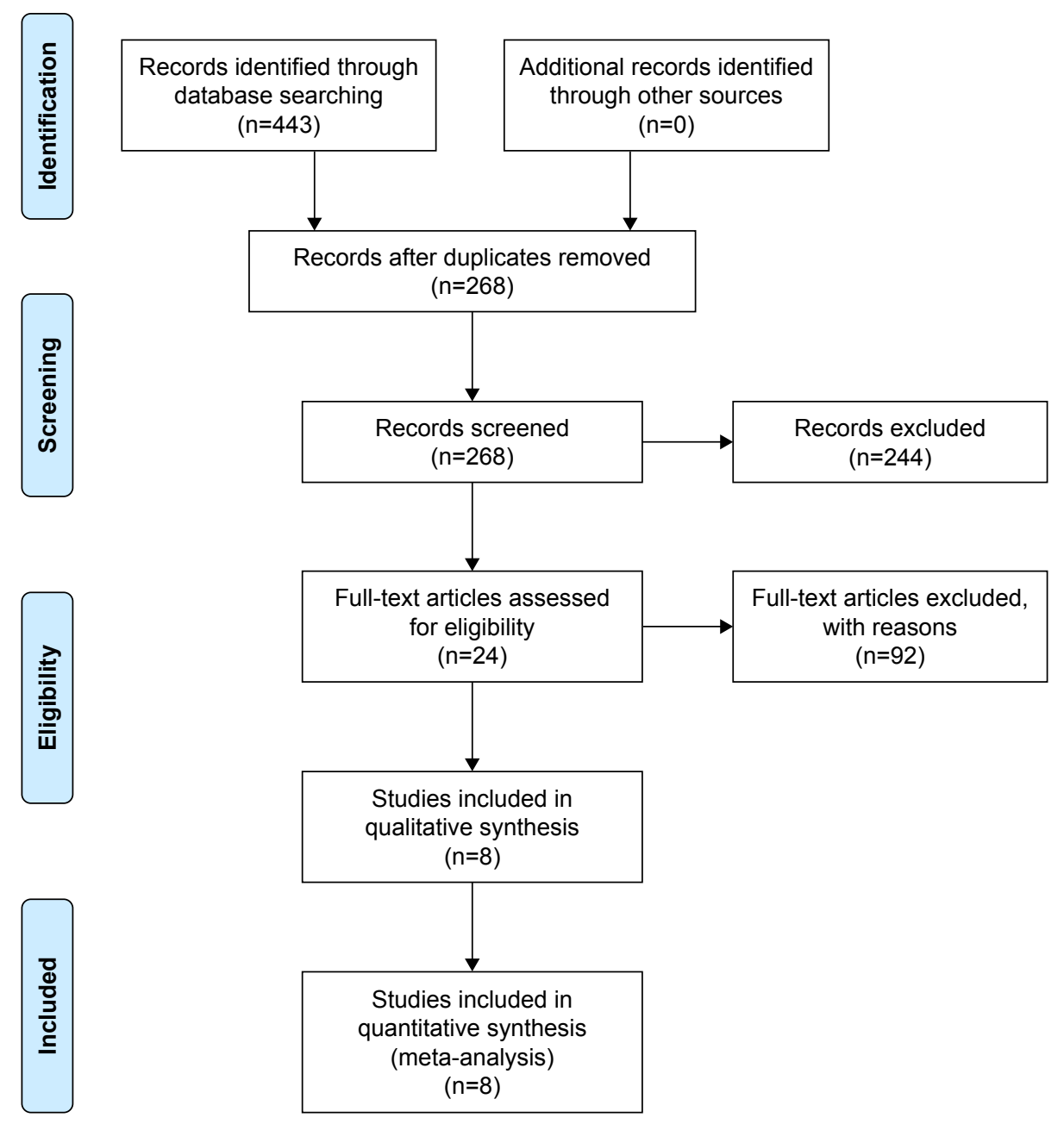

Figure I Flow diagram of study selection process.

rate of dose reduction or interruption is $33 \%$ (95\% CI: $24 \%$ to $42 \%$; Figure 7 ).

Different adverse events after alectinib treatment were reported in the 8 included studies. The 6 adverse events with the highest incidence are as follows: constipation (29\%, 95\% CI: $21 \%$ to $37 \%$ ), anemia ( $25 \%, 95 \%$ CI: $10 \%$ to $40 \%)$, myalgia $(18 \%, 95 \%$ CI: $15 \%$ to $21 \%)$, peripheral edema (18\%, $95 \%$ CI: $12 \%$ to $23 \%)$, dysgeusia ( $18 \%, 95 \%$ CI: $5 \%$ to $32 \%)$,

Table I Characteristics of the included studies

\begin{tabular}{|c|c|c|c|c|c|c|c|c|}
\hline Citation & $\begin{array}{l}\text { Number } \\
\text { of patients }\end{array}$ & $\begin{array}{l}\text { Median } \\
\text { age } \\
\text { (years) }\end{array}$ & $\begin{array}{l}\text { Median } \\
\text { duration of } \\
\text { follow-up } \\
\text { (months) }\end{array}$ & $\begin{array}{l}\text { Alectinib dose } \\
\text { and frequency }\end{array}$ & $\begin{array}{l}\text { Trial } \\
\text { phase }\end{array}$ & Baseline & $\begin{array}{l}\text { Treatment- } \\
\text { line }\end{array}$ & $\begin{array}{l}\text { Quality assessment (NOS } \\
\text { unless otherwise stated) }\end{array}$ \\
\hline Hida et $a^{23}$ & 103 & 61 & 12 & 300 mg PO BID & III & ALKi-naïve & Mixed & Cochrane ROB tool: high risk \\
\hline Peters et al ${ }^{15}$ & 152 & 58 & 18.6 & $600 \mathrm{mg}$ PO BID & III & Untreated & First-line & Cochrane ROB tool: high risk \\
\hline Seto et $\mathrm{a}^{26}$ & 46 & 48 & 7.6 & 300 mg PO BID & II & ALKi-naïve & Mixed & 6 \\
\hline Gadgeel et $\mathrm{al}^{27}$ & 47 & 56 & 4.2 & 300-900 mg PO BID & $\mathrm{I} / \mathrm{II}$ & CRZ-pretreated & Mixed & 4 \\
\hline Hida et $\mathrm{al}^{24}$ & 35 & 45 & NA & 300 mg PO BID & NA & Mixed & Mixed & 5 \\
\hline Ou et $\mathrm{al}^{28}$ & 138 & 52 & 7 & 600 mg PO BID & II & CRZ-pretreated & Mixed & 6 \\
\hline Shaw et $\mathrm{al}^{29}$ & 87 & 54 & 9.9 & $600 \mathrm{mg}$ PO BID & II & CRZ-pretreated & Mixed & 6 \\
\hline Iwama et $\mathrm{al}^{25}$ & 18 & 72 & 9.8 & 600 mg PO BID & II & Mixed & Mixed & 3 \\
\hline
\end{tabular}

Abbreviations: ALKi, anaplastic lymphoma kinase inhibitor; BID, twice a day; CRZ, crizotinib; NA, not available; NOS, Newcastle-Ottawa Scale; PO, take orally; ROB, risk of bias. 


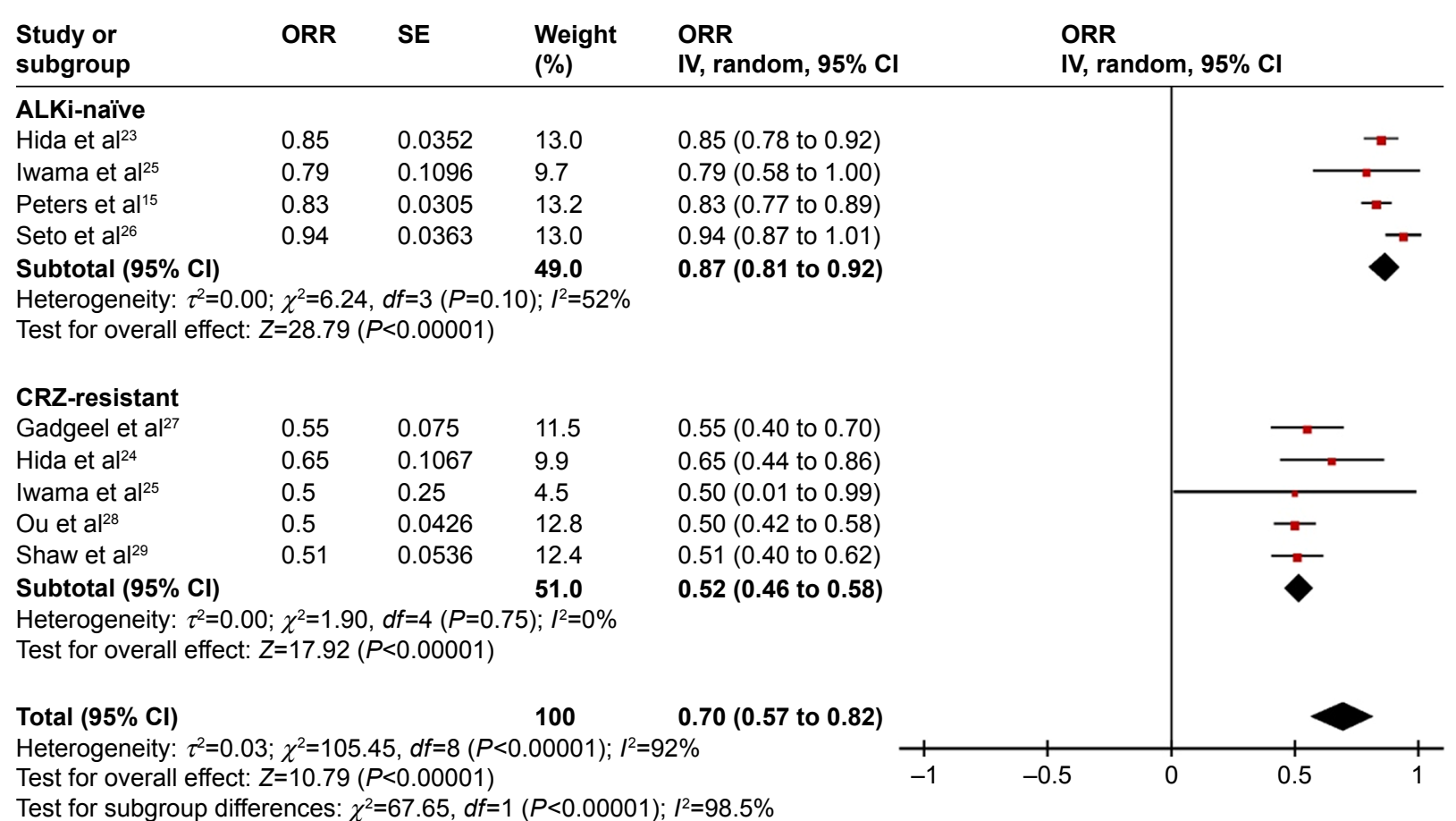

Figure 2 Meta-analysis of the ORR of ALKi-rearranged non-small cell lung cancer treated with alectinib.

Abbreviations: ALKi, anaplastic lymphoma kinase inhibitor; CRZ, crizotinib; ORR, overall response rate; SE, standard error; IV, inverse variance; Cl, confidence interval.

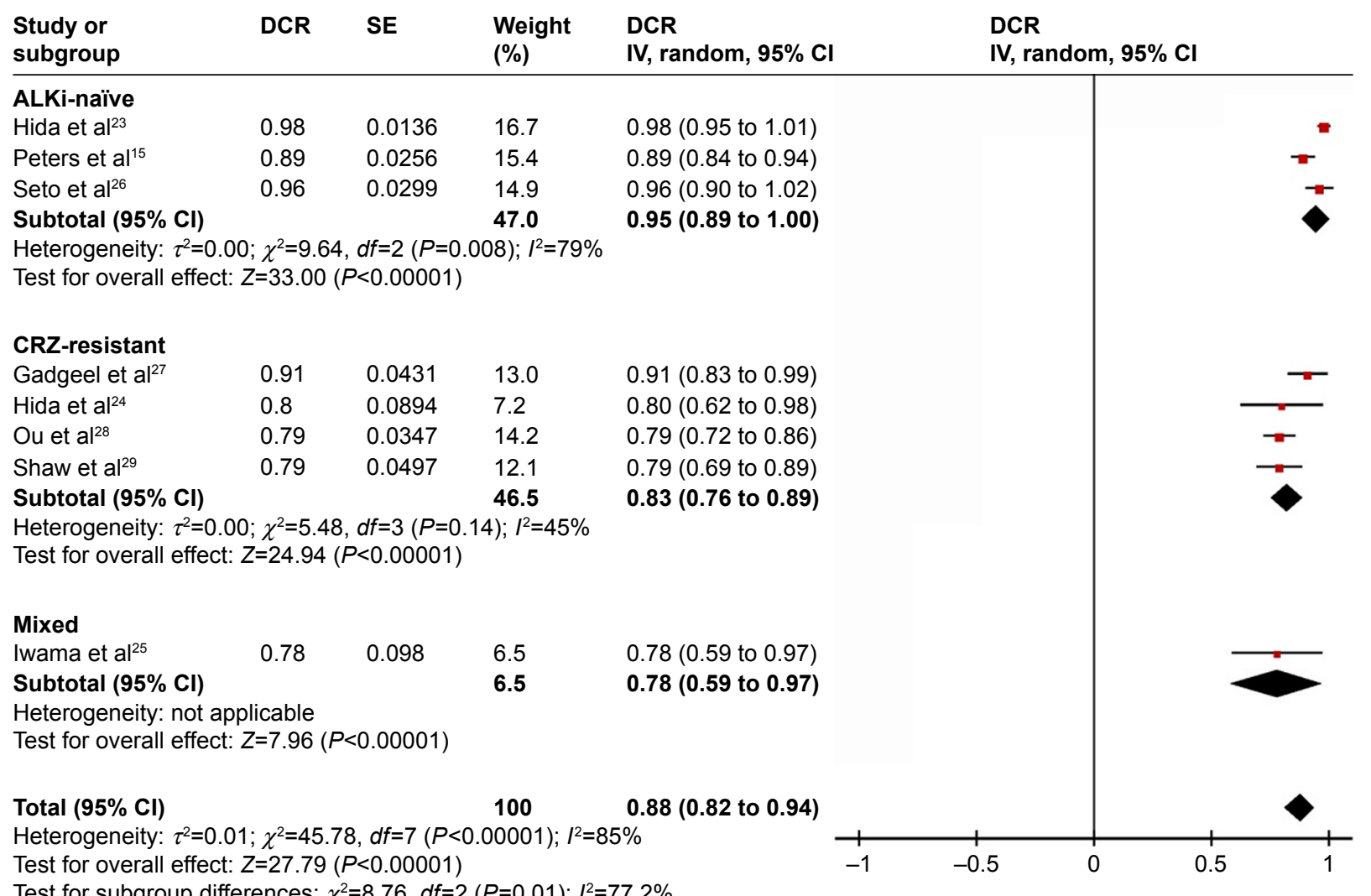

Figure 3 Meta-analysis of the DCR of ALKi-rearranged non-small cell lung cancer treated with alectinib.

Abbreviations: ALKi, anaplastic lymphoma kinase inhibitor; CRZ, crizotinib; DCR, disease control rate; SE, standard error; IV, inverse variance; Cl, confidence interval. 


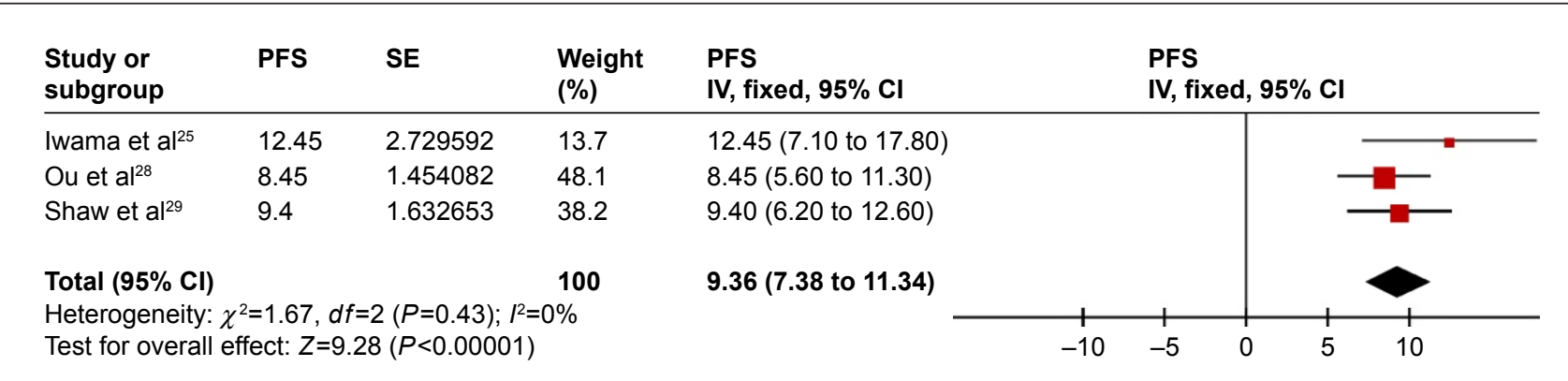

Figure 4 Meta-analysis of the PFS of ALK-rearranged non-small cell lung cancer treated with alectinib.

Abbreviations: ALK, anaplastic lymphoma kinase; PFS, progression-free survival; SE, standard error; IV, inverse variance; Cl, confidence interval.

and blood creatine phosphokinase (CPK) increase $(18 \%, 95 \%$ CI: $13 \%$ to $22 \%$; Figure 8 ). We also pooled the incidence of several other adverse events with lower event rates: aspartate aminotransferase increase (15\%, 95\% CI: $12 \%$ to $17 \%)$, nausea (14\%, 95\% CI: $11 \%$ to $16 \%)$, rash (14\%, 95\% CI: $10 \%$ to $17 \%)$, alanine aminotransferase increase $(13 \%, 95 \% \mathrm{CI}$ : $10 \%$ to $16 \%)$, blood bilirubin increase $(13 \%, 95 \% \mathrm{CI}: 9 \%$ to $17 \%$ ), headache (12\%, 95\% CI: $5 \%$ to $19 \%)$, diarrhea $(11 \%$, 95\% CI: $7 \%$ to $15 \%)$, neutropenia ( $8 \%, 95 \% \mathrm{CI}: 3 \%$ to $13 \%)$ and vomiting ( $8 \%, 95 \% \mathrm{CI}: 5 \%$ to $11 \%$; Figure S1).

\section{Publication bias}

For the ORR, PFS, and ORR of patients with baseline brain metastases, discontinuation rate, and the rate of dose reduction or interruption, their funnel plots were roughly symmetric (Figures S2 and $\underline{\mathrm{S} 3}$ ). The asymmetry of these funnel plots was further assessed with Egger's and Begg's tests, but yielded no statistically significant results. For the DCR outcome, however, there is a discrepancy between
Begg's test ( $p=0.386)$ and Egger's test $(p=0.027)$. Considering that Egger's test has higher sensitivity when the amount of included studies is $<20,{ }^{35,36}$ potential publication bias may exist according to Egger's test. The funnel plots of the adverse effects along with the results of Begg's and Egger's tests were further provided in the Supplementary materials (Figures S4 and S5; Table S2).

\section{Sensitivity analysis}

The "trim and fill" method was applied to evaluate the reliability of each result. For ORR, DCR, and the rate of dose reduction or interruption after alectinib treatment, their pooled results did not change significantly whether fixedor random-effect models were applied. No trimming was performed after the trim and fill analysis. This indicates that these results are quite robust.

For other pooled results, one or more studies were filled after the trim and fill analysis, so the results of these meta-analyses may be compromised. The pooled results

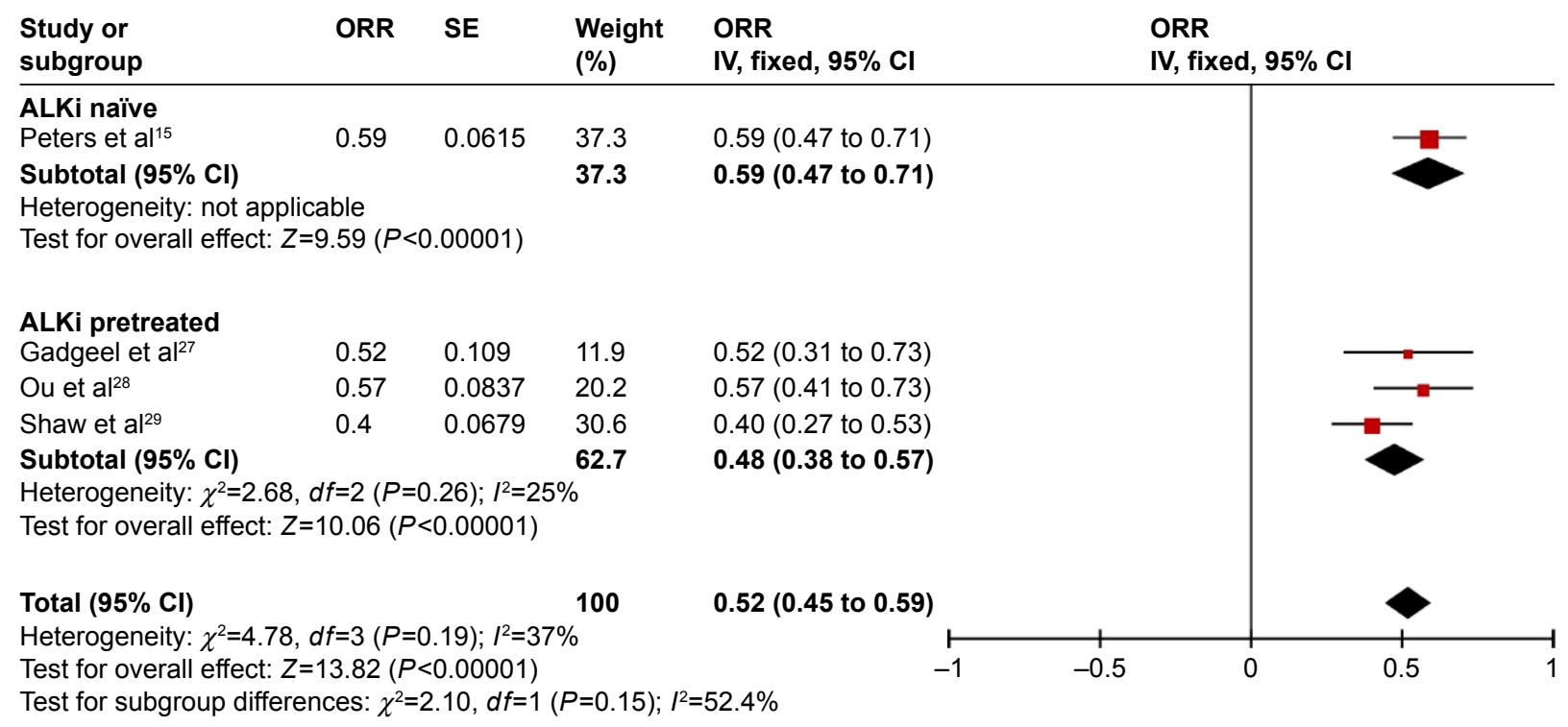

Figure 5 Meta-analysis of the ORR of alectinib-treated ALK-rearranged non-small cell lung cancer with brain metastases.

Abbreviations: ALK, anaplastic lymphoma kinase; ALKi, anaplastic lymphoma kinase inhibitor; CRZ, crizotinib; ORR, overall response rate; SE, standard error; IV, inverse variance; $\mathrm{Cl}$, confidence interval. 


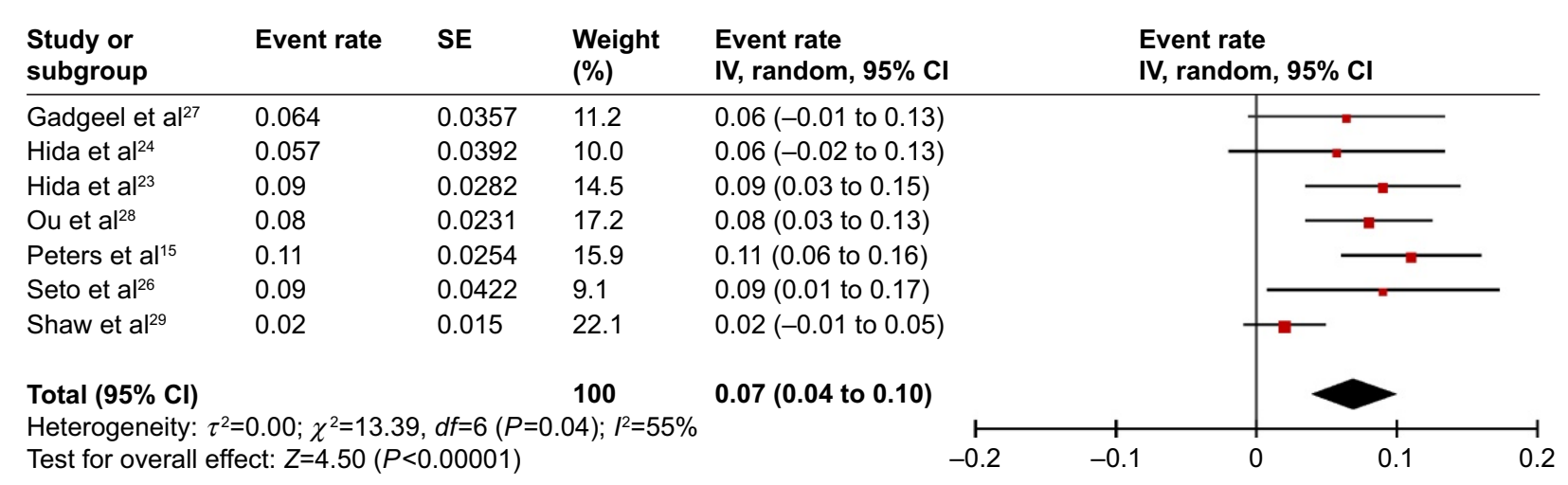

Figure 6 Meta-analysis of discontinuation rate after alectinib treatment.

Abbreviations: SE, standard error; IV, inverse variance; Cl, confidence interval.

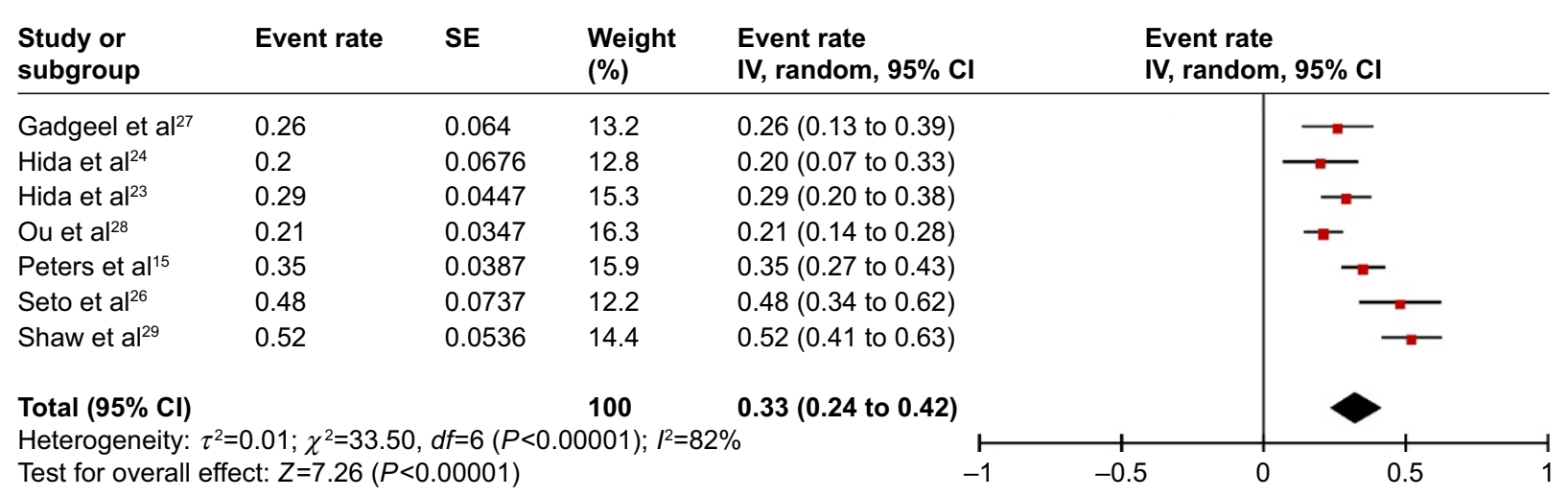

Figure 7 Meta-analysis of rate of dose reduction or interruption after alectinib treatment.

Abbreviations: SE, standard error; IV, inverse variance; $\mathrm{Cl}$, confidence interval.

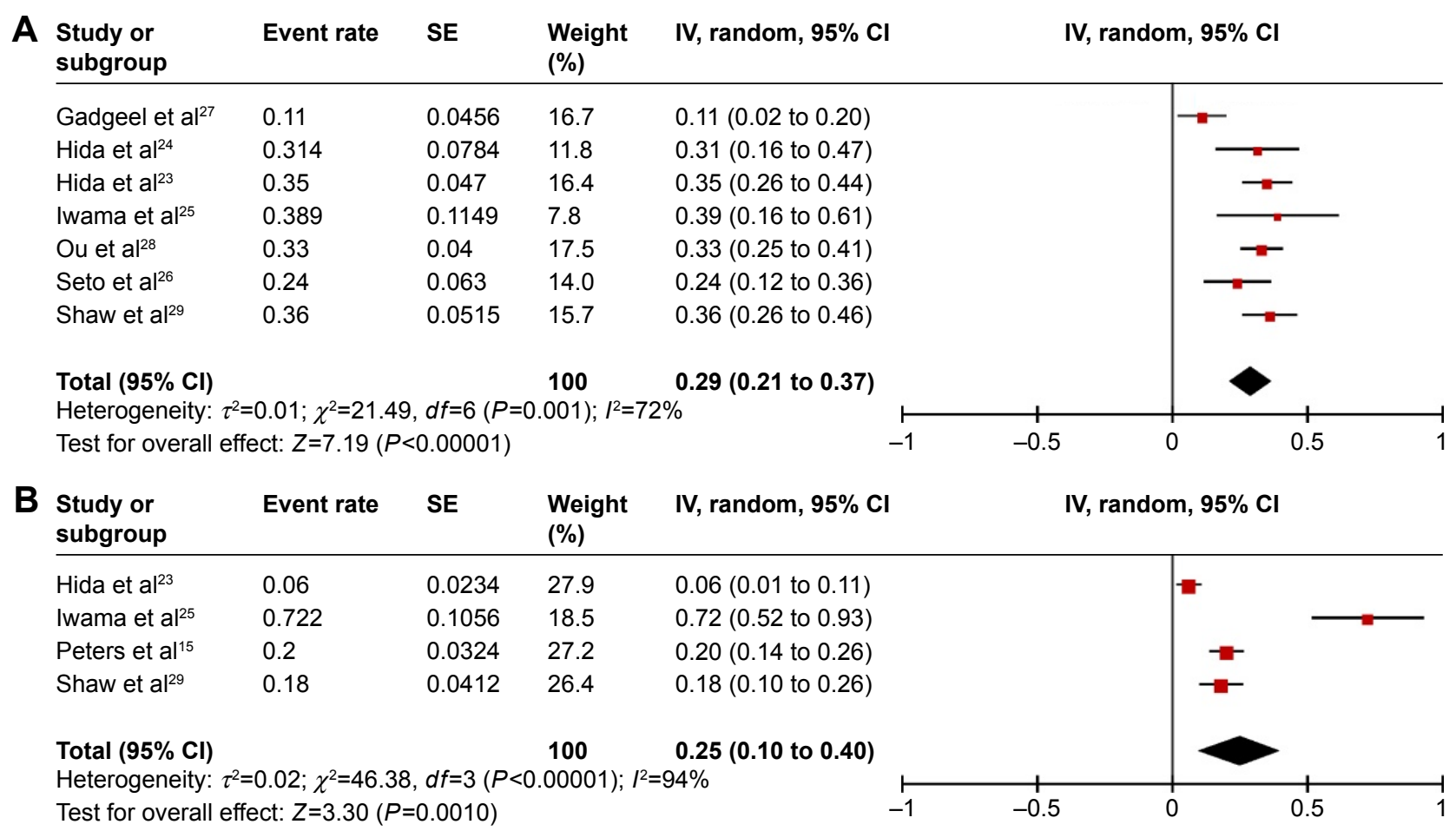

Figure 8 (Continued) 


\begin{tabular}{|c|c|c|c|c|c|c|c|c|}
\hline C & $\begin{array}{l}\text { Study or } \\
\text { subgroup }\end{array}$ & Event rate & SE & $\begin{array}{l}\text { Weight } \\
(\%)\end{array}$ & IV, fixed, $95 \% \mathrm{CI}$ & \multicolumn{2}{|c|}{ IV, fixed, $95 \% \mathrm{CI}$} & \\
\hline & Gadgeel et $\mathrm{al}^{27}$ & 0.17 & 0.0548 & 8.5 & $0.17(0.06$ to 0.28$)$ & & $\longrightarrow$ & \\
\hline & Hida et $\mathrm{al}^{23}$ & 0.16 & 0.0361 & 19.7 & 0.16 (0.09 to 0.23$)$ & & -- & \\
\hline & Ou et $\mathrm{al}^{28}$ & 0.23 & 0.0358 & 20.0 & $0.23(0.16$ to 0.30$)$ & & - & \\
\hline & Peters et al ${ }^{15}$ & 0.16 & 0.0297 & 29.1 & $0.16(0.10$ to 0.22$)$ & & - & \\
\hline & Seto et $\mathrm{al}^{26}$ & 0.13 & 0.0496 & 10.4 & $0.13(0.03$ to 0.23$)$ & & 一 & \\
\hline & Shaw et $\mathrm{al}^{29}$ & 0.24 & 0.0458 & 12.2 & 0.24 (0.15 to 0.33$)$ & & & \\
\hline & \multicolumn{2}{|c|}{ Total $(95 \% \mathrm{Cl})$} & \multicolumn{2}{|c|}{ Heterogeneity: $\chi^{2}=5.47, d f=5(P=0.36) ; I^{2}=9 \%$} & $0.18(0.15$ to 0.21$)$ & & 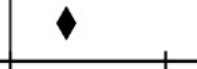 & \\
\hline & \multicolumn{4}{|c|}{ Test for overall effect: $Z=11.33(P<0.00001)$} & -1 & -0.5 & 0.5 & 1 \\
\hline \multirow[t]{10}{*}{$\mathbf{D}$} & $\begin{array}{l}\text { Study or } \\
\text { subgroup }\end{array}$ & Event rate & SE & $\begin{array}{l}\text { Weight } \\
(\%)\end{array}$ & IV, random, $95 \% \mathrm{CI}$ & \multicolumn{2}{|c|}{ IV, random, $95 \% \mathrm{Cl}$} & \\
\hline & Gadgeel et $\mathrm{al}^{27}$ & 0.17 & 0.0548 & 13.8 & $0.17(0.06$ to 0.28$)$ & & $\longrightarrow$ & \\
\hline & Hida et $\mathrm{al}^{23}$ & 0.09 & 0.0282 & 21.8 & $0.09(0.03$ to 0.15$)$ & & - & \\
\hline & Iwama et $\mathrm{al}^{25}$ & 0.167 & 0.0879 & 7.8 & $0.17(-0.01$ to 0.34$)$ & & & \\
\hline & Ou et $\mathrm{al}^{28}$ & 0.25 & 0.0369 & 19.0 & 0.25 (0.18 to 0.32$)$ & & $\rightarrow-$ & \\
\hline & Peters et $\mathrm{al}^{15}$ & 0.17 & 0.0305 & 21.1 & $0.17(0.11$ to 0.23$)$ & & & \\
\hline & Shaw et $\mathrm{al}^{29}$ & 0.23 & 0.0451 & 16.5 & 0.23 (0.14 to 0.32$)$ & & & \\
\hline & \multirow{2}{*}{\multicolumn{5}{|c|}{$\begin{array}{l}\text { Total (95\% CI) } \\
\text { Heterogeneity: } \tau^{2}=0.00 ; \chi^{2}=14.48, d f=5(P=0.01) ; l^{2}=65 \%\end{array}$}} & & & \\
\hline & & & & & & & & \\
\hline & \multicolumn{4}{|c|}{ Test for overall effect: $Z=6.13(P<0.00001)$} & -1 & -0.5 & 0.5 & 1 \\
\hline \multirow[t]{7}{*}{$\mathbf{E}$} & $\begin{array}{l}\text { Study or } \\
\text { subgroup }\end{array}$ & Event rate & SE & $\begin{array}{l}\text { Weight } \\
(\%)\end{array}$ & IV, random, $95 \% \mathrm{CI}$ & \multicolumn{2}{|c|}{ IV, random, $95 \% \mathrm{CI}$} & \\
\hline & Hida et al ${ }^{24}$ & 0.257 & 0.0739 & 21.8 & 0.26 (0.11 to 0.40$)$ & & - & \\
\hline & Hida et $\mathrm{al}^{23}$ & 0.18 & 0.0379 & 26.7 & $0.18(0.11$ to 0.25$)$ & & & \\
\hline & Peters et al ${ }^{15}$ & 0.03 & 0.0138 & 28.7 & $0.03(0.00$ to 0.06$)$ & & 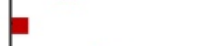 & \\
\hline & Seto et $\mathrm{al}^{26}$ & 0.3 & 0.0676 & 22.7 & $0.30(0.17$ to 0.43$)$ & & $\longrightarrow$ & \\
\hline & $\begin{array}{l}\text { Total }(95 \% \mathrm{Cl}) \\
\text { Heterogeneity: } \tau\end{array}$ & $=0.02 ; \gamma^{2}=34$ & $d f=3(P$ & $\begin{array}{l}100 \\
.00001) ; /\end{array}$ & $\begin{array}{l}\mathbf{0 . 1 8}(\mathbf{0 . 0 5} \text { to } \mathbf{0 . 3 2}) \\
91 \%\end{array}$ & & & \\
\hline & Test for overall e & ect: $Z=2.62($ & $0.009)$ & & -1 & -0.5 & 0.5 & 1 \\
\hline $\mathbf{F}$ & $\begin{array}{l}\text { Study or } \\
\text { subgroup }\end{array}$ & Event rate & SE & $\begin{array}{l}\text { Weight } \\
(\%)\end{array}$ & IV, fixed, $95 \% \mathrm{CI}$ & & $\mathrm{d}, 95 \% \mathrm{Cl}$ & \\
\hline & Gadgeel et $\mathrm{al}^{27}$ & 0.15 & 0.0521 & 18.7 & $0.15(0.05$ to 0.25$)$ & & $\longrightarrow-$ & \\
\hline & Hida et $\mathrm{al}^{23}$ & 0.17 & 0.037 & 37.1 & $0.17(0.10$ to 0.24$)$ & & - & \\
\hline & Seto et $\mathrm{al}^{26}$ & 0.15 & 0.0526 & 18.4 & $0.15(0.05$ to 0.25$)$ & & $\longrightarrow-$ & \\
\hline & Shaw et $\mathrm{al}^{29}$ & 0.22 & 0.0444 & 25.8 & $0.22(0.13$ to 0.31$)$ & & $\rightarrow-$ & \\
\hline & Total $(95 \% \mathrm{Cl})$ & & & 100 & $0.18(0.13$ to 0.22$)$ & & & \\
\hline & $\begin{array}{l}\text { Heterogeneity: } \chi \\
\text { Test for overall e }\end{array}$ & $\begin{array}{l}=1.50, d f=3( \\
\text { ect: } Z=7.78\end{array}$ & $\begin{array}{l}0.68) ; I^{2}= \\
0.00001)\end{array}$ & & -1 & -0.5 & 0.5 & 1 \\
\hline
\end{tabular}

Figure 8 Meta-analysis of event rate of several adverse events happened after alectinib treatment.

Notes: (A) Event rate of constipation. (B) Event rate of anemia. (C) Event rate of myalgia. (D) Event rate of peripheral edema. (E) Event rate of dysgeusia. (F) Event rate of blood creatine phosphokinase increase.

Abbreviations: SE, standard error; IV, inverse variance; Cl, confidence interval.

using different effect models as well as the trim and fill funnel plots are provided in the Supplementary materials (Figures S6-S8, Table S3).

\section{Discussion}

The current study has pooled the results of 8 clinical trials in order to evaluate the efficacy and safety of alectinib in the treatment of ALK+ NSCLC. Pooled results revealed that most patients who received alectinib treatment had their disease well controlled (DCR: 88\% and ORR: 70\%). Subgroup analyses showed that patients who never received ALKi before tend to have higher DCR and ORR than those who developed resistance after crizotinib treatment. The pooled PFS of alectinib-treated patients is 9.36 months, 
and subgroup analysis was not carried out due to limited numbers of included studies and mixed baselines. Currently, alectinib was approved by the FDA to treat crizotinibrefractory patients. ${ }^{9}$ It was also reported in a retrospective study that patients treated with alectinib alone had longer PFS and overall survival (OS) than those treated with crizotinib alone. However, patients who received sequential treatment with crizotinib and alectinib had longer OS than those who received alectinib alone. ${ }^{37}$ Currently, the PFS and OS results of first-line alectinib treatment are still missing in the 2 clinical trials comparing alectinib and crizotinib. ${ }^{15,23}$ Whether first-line alectinib treatment or sequential use of crizotinib and alectinib would lead to longer PFS and OS, further clinical trials are warranted to elucidate this question.

For the treatment of CNS metastases, the pooled intracranial ORR is 52\%. Subgroup analysis showed that ALKi-naïve patients tend to have better response than ALKi-pretreated patients (59\% vs $48 \%$ ). In the only Phase III clinical trial comparing alectinib and crizotinib that had reported intracranial efficacy, alectinib-treated patients had higher intracranial ORR than those treated with crizotinib (59\% vs 26\%). ${ }^{15}$ Apart from the difference of innate efficacy, higher CNS response may also result from increased blood-brain-barrier (BBB) penetration. ${ }^{20}$ In vivo experiments have shown that the brainto-plasma ratio of alectinib in animal models ranged from 0.63 to 0.94 , indicating that alectinib can well pass through BBB ${ }^{38}$ In contrast, it has been reported that the cerebrospinal fluid (CSF)-to-plasma ratio of crizotinib was $0.0026 .{ }^{39}$ This revealed the poor $\mathrm{BBB}$ penetration of crizotinib. Despite the potential difference in lipid solubility, the difference in $B B B$ penetrability may depend on a protein expressed in the $\mathrm{BBB}$ called P-glycoprotein (P-GP). Crizotinib and ceritinib molecules that had passed through BBB can be pumped out by P-GP efficiently, though alectinib is not a substrate of P-GP..$^{40}$ Therefore, the CSF concentration of alectinib can reach a relatively high level that can inhibit CNS metastases.

Aggregate results have shown that $7 \%$ of all patients discontinued alectinib treatment due to various adverse effects, and $33 \%$ of patients needed dose reduction or interruption. In the 2 Phase III trials that directly compared alectinib and crizotinib, both discontinuation rate and rate of dose reduction or interruption were lower in alectinib-treated patients. This had underscored the improved safety of alectinib. Frequently reported adverse effects with the highest incidence includes constipation (29\%), anemia (25\%), myalgia (18\%), peripheral edema (18\%), dysgeusia (18\%), and CPK increase (18\%). For most adverse events, the event rates were higher in crizotinibtreated patients rather than alectinib-treated counterparts ${ }^{15,23}$ and this was consistent with improved safety profile of alectinib. However, what is worth noting is that in both of these 2 random controlled trials comparing alectinib and crizotinib, myalgia and anemia were more frequently reported in alectinib-treated groups. ${ }^{15,23}$ Myalgia and anemia were also among the most frequently occurring adverse events according to our current study. Considering that alectinib outperforms crizotinib in almost all of the safety parameters, why does the next-generation ALKi have an even higher incidence of these 2 adverse events than the first-generation drug? More studies are warranted to reveal the underlying mechanism.

Admittedly, our current research is not without some limitations. Of the included studies, 6 of the 8 are Phase I or II clinical trials. Only 2 Phase III random controlled trials were included. Limited number of included studies and limited sample size have made our results susceptible to relative risks of bias. More random controlled trials comparing alectinib with crizotinib and/or chemotherapies need to be included to confirm our current results.

In summary, the results of this meta-analysis suggest that most patients would respond to alectinib treatment, or at least have their disease controlled (DCR: 88\% and ORR: 70\%). It seems that alectinib is a preferable drug to treat intracranial metastases of ALK+ NSCLC. Patients who never received ALKi treatment tend to have a better response than crizotinibrefractory patients. Generally, alectinib is well tolerated by ALK+ NSCLC patients. However, the incidences of few adverse events, such as myalgia and anemia were even higher in alectinib-treated patients compared with crizotinib-treated counterparts. Further clinical trials are warranted to update our meta-analysis and provide more insightful instructions for the clinical use of alectinib.

\section{Availability of data and material}

The datasets supporting the conclusions of this article are included within the article and its Supplementary materials.

\section{Acknowledgments}

This study was supported by the National Natural Science Foundation of China (81672267) and the Natural Science Foundation of Guangdong Province, China (2016A030313632).

\section{Author contributions}

All authors contributed toward data analysis, drafting and critically revising the paper, gave final approval of the version to be published, and agree to be accountable for all aspects of the work.

\section{Disclosure}

The authors report no conflicts of interest in this work. 


\section{References}

1. Molina JR, Yang P, Cassivi SD, Schild SE, Adjei AA. Non-small cell lung cancer: epidemiology, risk factors, treatment, and survivorship. Mayo Clin Proc. 2008;83:584-594.

2. Guo W, Liu S, Zhang X, et al. The coexpression of multi-immune inhibitory receptors on $\mathrm{T}$ lymphocytes in primary non-small-cell lung cancer. Drug Des Devel Ther. 2017;11:3367-3376.

3. Hanna N, Johnson D, Temin S, et al. Systemic therapy for stage IV nonsmall-cell lung cancer: American Society Of Clinical Oncology clinical practice guideline update. J Clin Oncol. 2017;35(30):3484-3515.

4. Katsenos S, Nikolopoulou M. Gemcitabine-induced severe peripheral edema in a patient with lung cancer. J Pharm Pract. 2012;25: 393-395.

5. Gota V, Kavathiya K, Doshi K, et al. High plasma exposure to pemetrexed leads to severe hyponatremia in patients with advanced non-small cell lung cancer receiving pemetrexed-platinum doublet chemotherapy. Cancer Manag Res. 2014;6:261-265.

6. Armas-Lopez L, Piña-Sánchez P, Arrieta O, et al. Epigenomic study identifies a novel mesenchyme homeobox2-GLI1 transcription axis involved in cancer drug resistance, overall survival and therapy prognosis in lung cancer patients. Oncotarget. 2017;8:67056-67081.

7. Zhang H, Hu B, Wang Z, Zhang F, Wei H, Li L. miR-181c contributes to cisplatin resistance in non-small cell lung cancer cells by targeting Wnt inhibition factor 1. Cancer Chemother Pharmacol. 2017;80(5): 973-984.

8. Soda M, Choi YL, Enomoto M, et al. Identification of the transforming EML4-ALK fusion gene in non-small-cell lung cancer. Nature. 2007; 448:561-566.

9. Roskoski R. Anaplastic lymphoma kinase (ALK) inhibitors in the treatment of ALK-driven lung cancers. Pharmacol Res. 2017;117: 343-356.

10. Shaw AT, Solomon B. Targeting anaplastic lymphoma kinase in lung cancer. Clin Cancer Res. 2011;17:2081-2086.

11. Kobayashi T, Fujimoto H, Gabazza EC. Efficacy of crizotinib in ALK fusion variants. J Thorac Dis. 2016;8:E1381-E1383.

12. Chen Y, Guo W, Fan J, et al. The applications of liquid biopsy in resistance surveillance of anaplastic lymphoma kinase inhibitor. Cancer Manag Res. 2017;9:801-811.

13. Wu J, Savooji J, Liu D. Second- and third-generation ALK inhibitors for non-small cell lung cancer. J Hematol Oncol. 2016;9:19.

14. Reungwetwattana T, Ou S-HI. Laying the groundwork to confront the final frontier of CNS metastasis in NSCLC with targetable driver mutations. J Thorac Oncol. 2016;11:281-283.

15. Peters S, Camidge DR, Shaw AT, et al. Alectinib versus crizotinib in untreated ALK-positive non-small-cell lung cancer. N Engl JMed. 2017; 377(9):829-838.

16. Maka VV, Krishnaswamy UM, Anil Kumar N, Chitrapur R, Kilara N. Acute interstitial lung disease in a patient with anaplastic lymphoma kinase-positive non-small-cell lung cancer after crizotinib therapy. Oxford Med Case Reports. 2014;2014:11-12.

17. Sawamura S, Kajihara I, Ichihara A, et al. Crizotinib-associated erythema multiforme in a lung cancer patient. Drug Discov Ther. 2015;9: $142-143$.

18. Iragavarapu C, Mustafa M, Akinleye A, et al. Novel ALK inhibitors in clinical use and development. J Hematol Oncol. 2015;8:17.

19. Masters GA, Temin S, Azzoli CG, et al. Systemic therapy for stage IV non-small-cell lung cancer: American Society of Clinical Oncology clinical practice guideline update. J Clin Oncol. 2015;3:3488-3515.

20. Sakamoto H, Tsukaguchi T, Hiroshima S, et al. CH5424802, a selective ALK inhibitor capable of blocking the resistant gatekeeper mutant. Cancer Cell. 2011;19:679-690.

21. Avrillon V, Perol M. Alectinib for treatment of ALK-positive nonsmall-cell lung cancer. Future Oncol. 2017;13:321-335.
22. Kodama T, Tsukaguchi T, Yoshida M, Kondoh O, Sakamoto H. Selective ALK inhibitor alectinib with potent antitumor activity in models of crizotinib resistance. Cancer Lett. 2014;351:215-221.

23. Hida $\mathrm{T}$, Nokihara $\mathrm{H}$, Kondo $\mathrm{M}$, et al. Alectinib versus crizotinib in patients with ALK-positive non-small-cell lung cancer (J-ALEX): an open-label, randomised phase 3 trial. Lancet. 2017;390:29-39.

24. Hida T, Nakagawa K, Seto T, et al. Pharmacologic study (JP28927) of alectinib in Japanese patients with ALK+ non-small-cell lung cancer with or without prior crizotinib therapy. Cancer Sci. 2016;107: 1642-1646.

25. Iwama E, Goto Y, Murakami H, et al. Alectinib for patients with ALK rearrangement-positive non-small cell lung cancer and a poor performance status (Lung Oncology Group in Kyushu 1401). J Thorac Oncol. 2017;12:1161-1166.

26. Seto T, Kiura K, Nishio M, et al. CH5424802 (RO5424802) for patients with ALK-rearranged advanced non-small-cell lung cancer (AF-001JP study): a single-arm, open-label, phase 1-2 study. Lancet Oncol. 2013; 14:590-598.

27. Gadgeel SM, Gandhi L, Riely GJ, et al. Safety and activity of alectinib against systemic disease and brain metastases in patients with crizotinibresistant ALK-rearranged non-small-cell lung cancer (AF-002JG): results from the dose-finding portion of a phase 1/2 study. Lancet Oncol. 2014;15:1119-1128.

28. Ou SH, Ahn JS, De Petris L, et al. Alectinib in crizotinib-refractory alk-rearranged non-small-cell lung cancer: a phase II global study. J Clin Oncol. 2016;34:661-668.

29. Shaw AT, Gandhi L, Gadgeel S, et al. Alectinib in ALK-positive, crizotinib-resistant, non-small-cell lung cancer: a single-group, multicentre, phase 2 trial. Lancet Oncol. 2016;17:234-242.

30. $\mathrm{Hu} \mathrm{H}$, Lin WQ, Zhu Q, Yang XW, Wang HD, Kuang YK. Is there a benefit of first- or second-line crizotinib in locally advanced or metastatic anaplastic lymphoma kinase-positive non-small cell lung cancer? A meta-analysis. Oncotarget. 2016;7:81090-81098.

31. Qian H, Gao F, Wang H, Ma F. The efficacy and safety of crizotinib in the treatment of anaplastic lymphoma kinase-positive non-small cell lung cancer: a meta-analysis of clinical trials. BMC Cancer. 2014; 14:683.

32. Moher D, Liberati A, Tetzlaff J, Altman DG. Preferred reporting items for systematic reviews and meta-analyses: the PRISMA statement. Int J Surg. 2010;8:336-341.

33. Higgins JPT, Green S. Cochrane Handbook for Systematic Reviews of Interventions. Chichester: John Wiley \& Sons; 2011.

34. Wells G, Shea B, O'Connell D, et al. The Newcastle-Ottawa Scale (NOS) for assessing the quality of nonrandomised studies in meta-analyses. Available from: http:/www.ohri.ca/programs/clinical_epidemiology/ oxford.asp. Accessed May 5, 2016.

35. Zhang T, Zhong W, Li B. Applied Methodology for Evidence-Based Medicine. Changsha: Central South University Press; 2011.

36. Maroufizadeh S, Almasi-Hashiani A, Omani Samani R, Sepidarkish M. Prevalence of retinopathy of prematurity in Iran: a systematic review and Meta-analysis. Int J Ophthalmol. 2017;10:1273-1279.

37. Ito K, Hataji O, Kobayashi H, et al. Sequential therapy with crizotinib and alectinib in ALK-rearranged non-small cell lung cancer-a multicenter retrospective study. J Thorac Oncol. 2017;12:390-396.

38. Kodama T, Hasegawa M, Takanashi K, Sakurai Y, Kondoh O, Sakamoto H. Antitumor activity of the selective ALK inhibitor alectinib in models of intracranial metastases. Cancer Chemother Pharmacol. 2014;74:1023-1028.

39. Costa DB, Kobayashi S, Pandya SS, et al. CSF concentration of the anaplastic lymphoma kinase inhibitor crizotinib. J Clin Oncol. 2011; 29:e443-e445.

40. Katayama R, Sakashita T, Yanagitani N, et al. P-glycoprotein mediates ceritinib resistance in anaplastic lymphoma kinase-rearranged non-small cell lung cancer. EBioMedicine. 2016;3:54-66. 


\section{Publish your work in this journal}

OncoTargets and Therapy is an international, peer-reviewed, open access journal focusing on the pathological basis of all cancers, potential targets for therapy and treatment protocols employed to improve the management of cancer patients. The journal also focuses on the impact of management programs and new therapeutic agents and protocols on
Dovepress

patient perspectives such as quality of life, adherence and satisfaction. The manuscript management system is completely online and includes a very quick and fair peer-review system, which is all easy to use. Visit http://www.dovepress.com/testimonials.php to read real quotes from published authors.

\footnotetext{
Submit your manuscript here: http://www.dovepress.com/oncotargets-and-therapy-journal
} 